\title{
PUBLIC INTERACTION OF WEB SELF-PRESENTATION
}

The article is focused on a specific area of copywriting - self-presentation of companies on the websites. It analyzes 190 webpages of smaller companies and 190 webpages of larger companies, compares their presentations and points out differences. The adaptation of the text to the search engine optimization and to the target audience and other aspects which create the specificity of copywriting are discussed.

Keywords: Copywriting, self-presentation, web, public.

\section{Introduction}

A significant qualitative shift has been recently observed in advertising and promotional texts. Promotion of products is associated with the very beginning of the exchange of goods. The way of communication with a customer has significantly changed thanks to electronic communication.

The primary objective of this article is to discuss the form of corporate web presentation focused on a customer. For this purpose, the qualitative analysis of the sample copywriting text has been conducted.

\section{Copywriting texts on the Internet}

The study discusses copywriting as a specific component of advertising, but also of the information in the Internet environment. It begins with a definition of this term, as the public are often confused by the expressions "copywriting" and "copyright" (these words are taken from English and they are pronounced in a similar way). There is no generally applicable definition in Slovakia; it can be most often found on blogs or websites of companies that offer such services. Abroad, there are a number of available valid materials, tutorials which were consulted during the process of the research. Selected resources on copywriting include A. Maslen [1]; J. Surgaman [2]; Manual of MoreNiche [3] D. Graham and J. Graham [4]; M. Stribbe [5]; M. Prokop [6]. Selected resources from the corporate communication and presentation on the web include: I. Pollach [7] and R. Fox [8]. "Copywriting is the act of writing words to sell a product, service, person, or idea. It uses persuasive language to set the voice and tone of a brand in the hope that people will identify with and buy into it" [9]. From a historical perspective, copywriters have worked for large agencies or for public-relations firms, pairing with Art Directors to write advertising copy that wins approval from the buying public. "Starting in the late '90s, the nature of copywriting began to change. The way in which people began consuming content changed the roles and responsibilities of copy, demanding both persuasive and contextually appropriate language that fit with a brand's style and aesthetic across different channels" [9]. This type of the copy/text can be also found in the Internet environment. In the article we discuss just the part of the copywriting text (form of corporate web presentation focused on a customer). The search engines create an integral component of the Internet space. In the $\mathrm{SEO}^{1}$ copywriting, there are texts which are not optimized for a potential customer or user, but for the search engines. As a result of this, various differences come into existence. An appropriate choice and placing of keywords in articles can "help in searching." This process is performed by making use of search engines (search engines, by complex indexing based on certain algorithms assign the order of search results for the keywords that are entered). The selection of appropriate keywords in the text is just one of many factors that are used with the aim to increase searchability. There is a significant interaction with the target audience for whom the text is intended. The interaction is related to the thinking process of a group, to the searching of the product or a service. Finally, it is related to the terms that are entered into the search engine. Answers to such questions could provide answers at the stage of an optimal drafting of the text.

\subsection{The reception of the public and of recipients}

The author of message should take into consideration not only the product or brand that is promoted, but also the target audience (often at the expense of opinion, aesthetic preferences,

${ }^{1}$ SEO - abbreviation of: Search Engine Optimization

\footnotetext{
* Elena Junova

Department of Mediamatics and Cultural Heritage, Faculty of Humanities, University of Zilina, Slovakia

E-mail: elena.junova@mediamatika.sk
} 
or artistic ambitions). The creator adapts the advertising communication to the customer (or to the potential recipient) To a large extent, the creator is limited by taste or purpose of the contractor who can also greatly affect the final outcome. Finally, the author of the advertisement has to incorporate into the advertising communication the particular product or service in order to highlight its qualities. If aesthetic criteria are preferred at the expense of actual information about the company, product or brand, there may be misunderstandings with regards to the communication with the recipient and as a consequence, it makes the advertisement ineffective. The creator of the message (either author or the group of artists) must find a symbiosis between information and advertising aesthetic component. Banyar also highlights the importance of traditions in the creation of the message. Tradition can be used as a source of inspiration for the author and, on the other hand, it assists in the process of decoding and in the interpretation of messages [10].

From this information, it can be deduced that the informational aspect in this case is in direct relation with the creative aspect. The creative component is used to provide notice to the user - together with graphics and the design component. These aspects act on the recipient at the same value scale as the aforementioned information aspect. The social aspect of the psychology of advertising communication is described by T. Deptova [11]. In order to approach the selected target audience, the author uses advertising information and the respective communication method. It may be associated with the choice of vocabulary (which the recipient understands and is familiar with), environment (which the recipient knows), or with the communicative situation and advertising ideas (those which impress the recipient). This is a form of simulation of private communication that is supported by elements of the corporate identity of the company. This form of communication is also supported by the choice of color, font, actors, music, and other factors pertaining to the selected target audience. Thus, even in advertising communication products penetrate into the vocabulary, which sometimes crosses the border between literary language and slang, or it moves the axis of the colloquial style of language, which is closer to the chosen market segment, is understandable and easily decodable. The advertising information (consistent with the familiar model $\mathrm{AIDA}^{2}$ or $\mathrm{ADAM}^{3}$ ) should attract the attention of the target audience if the message that is sent is to be accepted and correctly decoded by the target audience, e.g., words, phrases or sentences of particular importance, the choice of font type and size, image, color, plot and various forms of processing of audiovisual advertising. In many cases, however, we are faced with assembling and linking of these elements - as a result, there is an ambiguity in marketing communication. On the contrary, Rankov [12] refers to the fact

${ }^{2}$ AIDA - abbreviation of: attention, interest, desire or decision, action

${ }^{3}$ ADAM - abbreviation of: attention, desire or decision, action, memory that from the perspective of advertising communication (where on the one hand, there is often a professional institution involved in the production of advertising campaigns - advertising agency, or a specialized person and, on the other hand, there is a recipient, i.e., a potential customer), advertising is a highly professional (i.e. institutionalized) method of communication.

In general, it can be stated that the creative industries can be creative only to the extent that the customer or the receiver of the message is capable to face. With regards to the field of copywriting, there are developing strategies and recommendations for those who implement such type of communication and typical features for different categories of the offered reports and information content. The collective awareness of the problem, however, is often more intuitive or it is oriented to popular science. The scientific part of this process is not given much attention in Slovakia. In the process of the creation of texts for web, the interactions lie at the level of the originator (the originator is represented not only by the person of initiator but also by the executor), the message, the medium (by which the message is distributed) and the actual recipient (target audience). The interconnection of these components is inseparable, but the distribution of the individual components and the subsequent synthesis of generating characteristics help make the ongoing communication successful.

A more detailed insight into the issue of copywriting can be provided by its specification. One of the best-known Czech copywriters M. Prokop divides copywriting into four basic types according to the purpose of advertising: the first type is represented by direct sales of goods and services, the second type is concerned with generating interest and demand; the third type is associated with building awareness of goods and services, and finally, the fourth type is represented by corporate brand building [6]. The most extensive information contents are used in direct sales where a text should contain large amounts of information, and also specific technical details, examples of uses, independent assessments of other users or experts, answers to frequently asked questions, etc. In order to create interest and demand in concordance with the AIDA and ADAM models (both are discussed above), those who carry out the advertisement communication attempt to attract the attention of recipients (e.g., with different creative elements, the original text, etc.). The building of awareness of goods and services is applied in situations in which the goods cannot be sold at distance. In these cases, the general awareness of the product and service is reinforced. On the basis of this, a prospect can get interested in the product, and the product or service can be bought in retail. In these three cases, the language may vary to a significant degree - it ranges from a highly cultivated literary language through language containing a number of professional, technical terms taken over from English to specific language of particular community which is full of neologisms and slang words. In order to attract interest and demand in the product or in the company, 
the main priority is attracting the public attention. This process is usually implemented through interactive presentations, mobile ads (such as flashes, banners), attractive images that are almost always accompanied by texts, which are often short and concise, but also through texts that are shocking and inducing emotions (with suitably chosen words).

\section{Methodology}

With regards to the scope of copywriting, we will focus on a very specific area, namely on the presentation of companies on their websites.

We carried out the qualitative research, one of whose aims was partially to draw attention to the evaluation of the submitted information content to the public. Thirty-eight students of library and information studies (master's degree) were involved in this research in the academic year 2013/2014. They accounted for potential recipients of promotional communication products. Before the start of the process of qualitative research, the students had been familiarized with the specific features of copywriting texts which the advertiser should fulfill. One of their tasks was the observation and analysis - with the aim to determine whether the submitted copywriting texts of individual companies and their webpages met the appropriate features. Another aim was to determine how the webpages with copywriting texts appealed to them (this factor was investigated through an anonymous survey with open-type responses). This research method was evaluated as the most appropriate for the purposes of the research. Each student analyzed two websites of companies or organizations that were represented in two categories. Students completed the questionnaire according to the established criteria at the value scale - in the value from one to five + in each category had also open-type responses (into formal and content aspect). The formal content covers subcategories (colorfulness, creative component, readability, font size, structure). The content aspect covers subcategories (such as persuasive power of presented information, creative component, without orthography errors and mistakes, ability to capture and hold recipient attention).

The research sample consisted of copywriting webpage texts of companies and organizations that promote themselves, their services and products on the Internet. The selection of the research sample was conducted with regards to the relevance to the selected category. In general, it can be stated that the analysis focused on company websites with the orientation on a wide range of products, services. The focus was also placed on the websites of a non-profit sector. There were included companies whose main activity involved the presentation of mobile operators, insurance companies, consultation and finance companies, car producers, software products, electronics, food products (that included, e.g., mineral water, food vitamin supplements), voluntary organizations, companies focusing on cosmetic products, fashion clothes, sports clubs, and accommodation facilities. The websites were divided into two categories. The first category consisted of websites companies/organizations based in Slovakia, particularly with a regional scope. The main activity of the aforementioned companies and organizations focused primarily on the domestic market. Generally, their webpages were not much segmented and were primarily aimed at a narrower area of products/services. The second category consisted of websites of larger, international companies, firms or organizations whose main activities focus on the foreign market, but they also operate in Slovakia. Their webpages were mostly quite segmented and contained a large amount of information.

The study analyzes and discusses 190 sub-pages/webpages of smaller companies and 190 sub-pages/webpages of larger companies. It also compares various ways of presenting information to the user and points out the differences which are present in copywriting texts of this type. The study also presents mutual interlink between creative aspect and other phenomena of copywriting texts (such as the information environment, the process of adaptation of the text to the terms set by SEO, adaptation to the target audience). The informational aspect is a natural part of these texts as well.

Each analysis includes home page and four other sub-pages/ webpages of a company. We chose only subpages that contain at least 200 words on a given webpage/subpage. In both analytic procedures, this included the analysis of the content of 38 websites (a set of pages).

\section{Results}

The students evaluated the copywriting texts verbally.

On the basis of their description, texts were subsequently classified into three levels. The first category, evaluated as the category of the lowest quality, consists of texts of poor quality, with many mistakes. Furthermore, the texts were not properly organized and they were not adapted to readers and were written in an elaborate style, etc.

The second category consists of texts of an average standard. Within this category, the texts were adapted to customers, but they also obtained errors that impeded proper recipients' understanding. Moreover, the texts did not seem to be sufficiently organized, there was a problem with the orientation on a page, etc.

The last category consists of texts on a professional level which were positively evaluated by recipients with regards to their content and formal aspects.

We noticed a significant difference between the level of copywriting texts of smaller companies and of larger companies. The results can be seen in the graph (Fig. 1): 


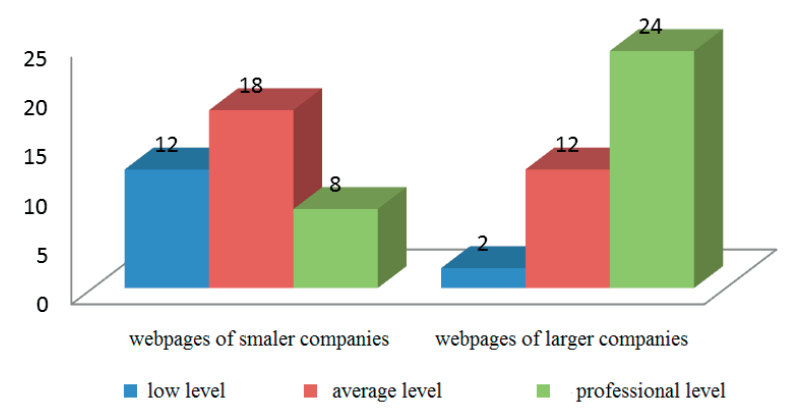

Fig. 1 Levels of copywriting texts based on respondents' evaluation

The graph shows significant differences in respondents evaluation of webpages (copywriting texts, information content, visual impression) between smaller and larger companies. With smaller companies, we recorded a high number of evaluations at a low level - $12(32 \%)$ compared to larger companies where only $2(5 \%)$ of respondents rated the level of the analyzed site as low. The average level was achieved in most of smaller companies' webpages - 18 (47\%) and a high, professional level with a positive response from the respondents amounted to only $8(21 \%)$ of webpages. In comparison with these results, $24(63 \%)$ of respondents rated the level of webpages of larger companies as very high and positive, and 12 (32\%) of respondents assigned them the average level.

Students, being representatives of ordinary recipients or of potential customers reported an improper processing of information content with regards to the formal and content aspect as the most common reasons related to the reduction of the level of the webpage. In some cases, the information content was not adapted to the recipient (with regards to formulation, to the length of sentences or poorly chosen font and font size which caused problems with the readability of texts). Respondents positively evaluated those cases in which the information content was properly adapted to the offered product or service. They also positively evaluated cases in which the information was given clearly, convincingly and creatively. The creative component was seen as a major positive which enabled to distinguish particular company from other companies and enabled to catch the attention of respondents. The creative component did not include only the information content, but it also included the graphic design and the use of interactive elements. The visual impact was rated as equally important element as the information contents. From the obtained responses, we observed perception of respondents appellative components. Information and rational appeals were used and they depended on the nature of the offered products and services. Together with emotional appeals which were seen as added values, they created a whole with a synergistic effect (when appeals were appropriately used). This issue is highlighted by Vopalenska who underlines the fact that emotions themselves remain in memory for a longer period of time than arguments.
Thus, if we intend to anchor certain information, we should use tools that evoke emotions.

The main role of appeals is to influence opinions, attitudes and values. As a consequence, the brand, product, service or procedure can become the object of recipient's attention, interest, desire or action. Furthermore, the result of this action will be fixed in his/her mind [13].

In the analyzed type of information content and information environment (more specifically, that of copywriting texts and of webpages where these texts are located), it is essential to take into account research and studies conducted in the area of information behavior of ICT users.

In addition to the above mentioned aspects, it is context that plays an important role in the process of searching and processing of the information. Context is generally considered to be not only specific discipline or area of activity - it also stands for the type of solving social and organizational framework, status and function of a person in a team or organization, time, project finance, resource availability, interdisciplinarity theme, etc. Context can be divided into external (it includes social and cultural aspects of information behavior) and internal (it includes sensorimotor, cognitive, affective component of information behavior) [14]. These individual components contribute to better understanding of user's information behavior

\section{Conclusion}

In the field of advertising communication, the interconnection between information and creative industries can be observed. A proper adaptation of particular components increases the effectiveness of communication. The aspects of informational interaction and creative aspects of social perception are irreplaceable, as the recipient is a human. A person interacting with the environment that surrounds them is the subject of many scientific studies. The acquired knowledge will be applied in many areas due to its considerable interdisciplinary character. Message, as a part of information and creative industries can have a variety of forms. In this paper, we focused on copywriting texts in the online environment. Their perception depends on selected content and form and on the particular focus of interest of a recipient in the given area as well.

The qualitative research suggests differences in the quality of submitted webpages of smaller and larger companies towards the public. As it is assumed, the level of form and content of larger companies is directly proportional to the amount of money and professional activity involved in the production. Overall, the respondents identified the following as the most serious shortcomings: unprocessed information contents (a number of errors or a lack of clarity) together with optical - visual shortcomings. 
The specificity of copywriting texts enhances their advertising message. Their attraction and creativity are often reduced due to a number of errors of different nature. It is the consistency of the content and of the form that plays an important role in the success of commercial texts.
The relevance of our scientific study lies in the fact that it highlights the individual aspects that affect copywriting. These are grounded in the information interaction and in the advancement of knowledge in the area that deserves scientific attention.

\section{References}

[1] MASLEN, A.: Great Copywriting Ideas: From Leading Companies around the World, Singapore : Marshall Cavendish Business, 225 p., 2009, ISBN 978-0-462-09973-6.

[2] SURGAMAN, J.: The Adweek Copywriting Handbook: The Ultimate Guide to Writing Powerful from One of America's Top Copywriters Advertising and Marketing Copy, New Jersey : John Wiley \& Sons, Inc., Hoboken, 2007, ISBN - 13: 978-0-470-05124-5, ISBN - 10: 0-470-05124-8.

[3] MORENICHE: Writing Effective Sales Copy for the Web \& General Tips for Your Site [online], MoreNiche Affiliate Tutorials [quote 2013-11-16]. Available at: http://www.twisttraining.com/archive/mn/effective-sales-copy.php

[4] GRAHAM, D., GRAHAM, J.: Can Do Writing: The Proven Ten - Step System for Fast and Effective Business Writing, New Jersey : John Wiley \& Sons, Inc., Hoboken, 2009, 204 p. ISBN 978-0-470-44979-0.

[5] STIBBE, M.: Days to Better Business Writing [online], 2010 [quote 2013-12-01]. Available at: http://www.badlanguage.net/ebook

[6] PROKOP, M.: Writing for the Web - and Do Form Text on the Web [online]. In: Interval.cz. 2004 [quote 2013-11-11]. Available at: http://interval.cz/clanky/piseme-pro-web-cile-a-formy-textu-na-webu/

[7] POLLACH, I.: Corporate Self-presentation on WWW: Strategies for Enhancing Usability, Credibility and Utility, Corporate Communications: An International J., vol. 10, No. 4, 2005, pp. 285-301, Emerald Group Publishing Limited. pp. 1356 - 3289. DOI $10.1108 / 13563280510630098$

[8] FOX, R.: Corporations' ideologies: A New Subfield of Study of Corporate Communication [online], Corporate Communications: An International J., vol. 11, No. 4, 2006, pp. 353-370. Emerald Group Publishing Limited. pp. 1356 - 3289. DOI $10.1108 / 13563280610713842$

[9] SIMON, D. P.: Copywriting Across Channels [online]. UXmatters, 2013 [quote 2014-05-10]. Available at: http://www.uxmatters. com/mt/archives/2013/09/copywriting-across-channels.php

[10] BANYAR, M.: Art and Advertising-signs of Artistic and Commercial Communication [online], pp. 118-146. In: HORNAK, P. et al., 2009. Advertisement 09: Proc. of scientific studies on questions of theory and history of advertising and public relations, Bratislava: Comenius University, Department of Marketing Communication, Book Publishing \& Book, 2009, 168 p., ISBN: 978-80-9702470-3, [quote 2013-11-21]. Available at: http://www.fphil.uniba.sk/uploads/media/Reklama_09.pdf

[11] DEPTOVA, T.: Spoken Form of the Language in Advertising Communicator, pp. 266-276, In: Kralcak, 2008: The spoken form of the language in the media, 2008, Nitra, 318 p., ISBN 978-80-8094-293-9

[12] RANKOV, P.: Popular Culture, Mass Media Communication and Advertising [online], pp. 147-156. In: HORNAK, P. et al., 2009. Advertisement 09: Proc. of scientific studies on questions of theory and history of advertising and public relations, Bratislava: Comenius University, Department of Marketing Communication, Book Publishing \& Book, 2009, 168 p., ISBN: 978-80-9702470-3, [quote 2013-11-21]. Available at: http://www.fphil.uniba.sk/uploads/media/Reklama_09.pdf

[13] VOPALENSKA, E.: Advertising Persuasion - Appeals and other Means of Advertising Stylization [online], 2009, p. 47-71. In: HORNAK, P. et al., 2009. Advertisement 09, Proc. of scientific studies on questions of theory and history of advertising and public relations, Bratislava: Comenius University, Department of Marketing Communication, Book Publishing \& Book, 2009, 168 p., ISBN: 978-80-970247-0-3 [quote 2013-11-21]. Available at: http://www.fphil.uniba.sk/uploads/media/Reklama_ 09.pdf

[14] STEINEROVA, J.: Human Information Behavior - Users Information Regarding [online]. Ikaros, Electronic J. on Information Society, 2005, vol. 9, No. 9 [quote 2013-12-11]. Available at: http://www.ikaros.cz/informacne-spravanie-cloveka- \% E2 \% 80 \% 93 - information - across - the - context. 